\title{
A DEFORMAÇÃO DO SUJEITO NO ROMANCE SOZABOY, DE KEN SARO-WIWA
}

\section{THE DEFORMATION OF THE SUBJECT IN THE NOVEL SOZABOY, BY KEN SARO-WIWA}

\author{
André Cechinel ${ }^{1}$ \\ Michelle Maria Stakonski Cechinel ${ }^{2}$
}

\begin{abstract}
RESUMO: O presente artigo propõe-se a defender o argumento de que, ao contrário do que a breve história de sua recepção nos diz, não há "formação" alguma em jogo no romance Sozaboy, do escritor e ativista político e ambiental nigeriano Ken Saro-Wiwa, ao menos não segundo os termos da Bildung ou do Bildungsroman. Para apresentar o argumento em questão, o texto divide-se em dois momentos fundamentais: primeiramente, realiza uma rápida introdução ao significado histórico dos conceitos que aqui nos cabem, "formação" (Bildung) e "romance de formação" (Bildungsroman); a seguir, tomando como pano de fundo a exposição realizada, o artigo analisa o romance Sozaboy, assinalando que, menos que um "romance de formação", Saro-Wiwa descreve um processo deformativo singular, que, como tal, pede do leitor uma outra epistemologia, uma epistemologia negativa da destruição do sujeito.
\end{abstract}

PALAVRAS-CHAVE: Ken Saro-Wiwa; Sozaboy; Bildung; deformação.

ABSTRACT: This article intends to defend the argument that there is no "formation" at stake in Sozaboy, novel by writer and political and environmental activist Ken Saro-Wiwa, at least not according to the terms of the Bildung or the Bildungsroman. In order to present this thesis, the text is divided into two fundamental parts. First, it presents a brief introduction to the historical meaning of the concepts here discussed, "formation" (Bildung) and "novel of formation" (Bildungsroman). After that, the article analyzes the novel Sozaboy, noting that, less than a "novel of formation," Saro-Wiwa describes a singular deformative process, which, as such, requires from the reader another epistemology, a negative epistemology concerning the destruction of the subject.

KEYWORDS: Ken Saro-Wiwa; Sozaboy; Bildung; deformation.

1 Professor do curso de letras e do mestrado em educação da UNESC. E-mail: andrecechinel@gmail.com 2 Professora do Departamento de História da UNESC. E-mail: miimss@gmail.com 


\section{INTRODUÇÃO}

Apesar de objeto recente de uma dissertação de mestrado defendida na Universidade Estadual de Londrina, ${ }^{3}$ o romance Sozaboy (1985), do escritor e ativista nigeriano Ken Saro-Wiwa, é ainda pouco conhecido no Brasil, possivelmente por permanecer sem tradução para a língua portuguesa. Já o nome do autor e sua história nos são mais familiares: como resultado das constantes críticas e denúncias dirigidas à atividade petrolífera e à destruição ambiental por ela causada na região nigeriana do Delta do Rio Níger, habitada pelos Ogoni, Saro-Wiwa foi acusado de liderar um atentado contra alguns dos chefes Ogoni que apoiavam o governo - e que, portanto, facilitavam a manutenção das regulamentações precárias para a extração do petróleo na região -, sendo enforcado em 10 de novembro de 1995, juntamente com os demais membros do grupo conhecido como os Nove de Ogoni (the Ogoni Nine). Acompanhada de perto por empresas como a Shell e a Chevron, diretamente interessadas no julgamento dos Nove de Ogoni, a execução de Saro-Wiwa alcançou grande repercussão midiática, levando à suspensão da Nigéria por três anos da Commonwealth of Nations (Comunidade das Nações), associação de 53 estados composta, em sua grande maioria, por ex-colônias britânicas.

Em linhas gerais, narrado em primeira pessoa, Sozaboy conta a história de Mene, um jovem aprendiz de motorista que sonha tornar-se um soldado (sozaboy = soldier boy, “jovem soldado") para assim conquistar o respeito dos demais habitantes de Dukana, a comunidade onde vive. Conforme indica o subtítulo do romance, a novel in rotten English, Sozaboy foi escrito em uma língua bastante particular, chamada pelo autor de rotten English ("inglês roto"), "uma mistura de pidgin inglês nigeriano, um inglês 'macarrônico' e lampejos de um inglês correto e até mesmo idiomático" (SARO-WIWA, 1994, p. xiii). É valendo-se dessa linguagem híbrida, fragmentária e, no entanto, extremamente lírica, que Saro-Wiwa retrata o profundo desconhecimento de Mene em relação às atrocidades cometidas durante as guerras, ou, neste caso em particular, durante a Guerra Civil Nigeriana, conhecida como a Guerra de Biafra. ${ }^{4}$ Embora queira juntar-se aos combatentes do exército e utilizar o uniforme que admira e as armas que empoderam, apropriando-se, ademais, de uma linguagem

3 "Desalienação e a configuração do Bildungsroman em Sozaboy: a novel em rotten English, de Ken Saro-wiwa", de Celina de Oliveira Barbosa Gomes.

4 A Guerra de Biafra, ou Guerra Civil Nigeriana, foi um conflito de secessão civil que ocorreu entre os anos de 1967 e 1970 , devido à tentativa de emancipação do território de Biafra, uma região no sudoeste da Nigéria com mais de $71 \mathrm{mil} \mathrm{km2.} \mathrm{A}$ Guerra de Biafra se insere no contexto das tensões do processo de descolonização da Nigéria, após a Inglaterra reconhecer a emancipação da nação, em 1960. Em meados da década de 60 do século passado, a nação autônoma recém-criada dividia seu território em três regiões, que aglutinavam uma enorme diversidade étnica. Os três maiores grupos - haussás-fulanis, localizados no norte da Nigéria, Iorubas, no sudoeste, e igbos, na região sudeste - disputavam espaços de representatividade política e o governo central. As tensões aumentaram quando, em janeiro de 1966, um grupo de oficiais de maioria igbo deu um golpe de Estado, assassinando o primeiro-ministro, Abubakar Tafawa Balewa, e os governadores da região norte e oeste da Nigéria, Ahmadu Bello e Ladoke Akintola. Após seis meses do primeiro golpe, um grupo de militares haussás-fulanis da região Norte organizou um contra-golpe, e, com a tomada do poder e o apoio popular, passou a perseguir a etnia igbo. Nesse panorama de disputas políticas, os líderes igbo decidiram em maio de 1967 separar o território de Biafra do restante do país, sofrendo, a partir de então, violenta repressão armada e bloqueio estatal de alimentos e remédios. É importante ressaltar que o governo nigeriano havia recém descoberto jazidas petrolíferas na região de Biafra, e esta descoberta acirrou os embates pelo território. O conflito, extremamente midiatizado internacionalmente, se encerrou em 1970, quando Biafra foi reincorporada à Nigeria. Segundo Elikia M’Bokolo, "a guerra matou 100 mil soldados, mas fez entre 500 mil e 2 milhões de mortos civis, principalmente devido à fome provocada ou agravada pelo bloqueio de Biafra pelas tropas federais” (2011, p. 650). 
bastante sedutora - "The man with fine shirt stood up. And begin to talk in English. Fine fine English. Big big words. Grammar. 'Fantastic. Overwhelming. Generally. In particular and in general'"' (SARO-WIWA, 1994, p. 46) -, Mene ignora por completo a natureza do conflito a que está prestes a se juntar, tentando fabricar ou projetar um sentido mínimo que justifique o seu ingresso no campo de batalhas: "Young young boys like myself, all of them with gun and uniform. [...] When I see all their uniform shinning very very nice to see, I cannot tell you how I am feeling. Immediately, I know that this soza is wonderful thing" 6 (SARO-WIWA, 1994, p. 46). Contudo, encerrada a sua passagem pelo exército, Mene descobre a duras penas a destruição promovida pela guerra e o preço que ela cobra daqueles que dela participam direta ou indiretamente, a saber, a fragmentação da identidade, a destruição dos laços familiares e comunitários, a fragilização do vínculo com os outros e a perda da capacidade de atribuir sentido às experiências vividas.

Ao contrário da tese frequentemente defendida e difundida em torno de Sozaboy, segundo a qual a obra de Ken Saro-Wiwa constituiria um "romance de formação" (Bildungsroman) por retratar a tomada de consciência de Mene quanto ao verdadeiro significado da guerra (cf., por exemplo, Gomes [2015], Nnolim [2010] e Simola [1999]), o presente texto propõe-se a sustentar justamente o argumento de que não há formação alguma no livro em questão, ao menos não nos termos da Bildung romântica ou de sua apropriação posterior, e que ler Sozaboy como Bildungsroman significa alargar o conceito até o ponto de sua própria dissolução. A fim de defender a hipótese em pauta, o artigo divide-se em dois momentos fundamentais: primeiro, revisita tanto a ideia de Bildung quanto de Bildungsroman, de modo a esclarecer, de forma introdutória, o percurso mínimo que particulariza e dá sentido a esses conceitos; a seguir, atravessada a fase de conceituação dos termos que aqui nos importam, o texto parte para a análise propriamente dita de Sozaboy e de seu personagem principal e narrador, Mene, a fim de assinalar de que modo o seu percurso se singulariza uma vez comparado aos casos emblemáticos que consolidaram a ideia de Bildungsroman para além de sua origem na literatura alemã. Em poucas palavras, a "formação" de Mene decorre, antes de mais nada, da negação ou deformação de seu lugar como sujeito no mundo, o que faz com que, ao fim da jornada supostamente "formativa", ele possa tão somente conviver com as sombras daquilo que antes conferia sentido à sua existência.

\section{SOBRE A BILDUNG E O “ROMANCE DE FORMAÇÃO” (BILDUNGSROMAN)}

Ainda que se possa dizer que a tarefa da filosofia corresponde àquela de fabricar ou lançar conceitos, é certo que todo conceito proposto possui uma historicidade própria e vital para o seu funcionamento, sem a qual ele corre o risco de girar em falso em torno de si mesmo, longe de aderir de forma significativa aos objetos. Em outras palavras, os conceitos

\footnotetext{
5 "O homem com a camisa bonita levantou. E começou a falar em inglês. Um inglês muito muito legal. Palavras bem bem grandes. Gramática pura. 'Fantástico. Impressionante. Geralmente. Em particular e em geral”. Todas as traduções do romance Sozaboy para o português são de minha autoria.

6 Garotos bem bem jovens como eu, todos eles com arma e uniforme. [...] Quando vejo o uniforme deles brilhando bem bem bom de ver, nem sei dizer o que eu começo a sentir. Imediatamente, percebo que essa coisa de ser soldado é muito legal".
} 
não têm validade perene, não são uma mercadoria cuja manipulação atende ao livre desejo de seus usuários, nem podem ser forçados a qualquer artefato sem o risco de um alargamento que, como dito, torna a sua atuação inofensiva ou inoperante. Ora, talvez esse seja justamente o caso da expressão "romance de formação" (Bildungsroman) no campo da literatura: insistir na ideia de formação segundo os termos da Bildung significa, hoje, forçar o texto literário a um conceito que perdeu o instante de sua efetividade. Não por acaso, muitos dos romances contemporâneos lidos a partir da Bildung precisam de uma mediação tamanha para se adequar à noção, que o diagnóstico final é via de regra um suposto uso crítico capaz ao mesmo tempo de aderir ao termo e problematizá-lo, não porque a obra de fato o faça ou se situe nas fronteiras da Bildung, mas apenas porque o conceito já não alcança mais o momento do seu uso, e sua aplicação só se torna viável uma vez aparadas as devidas arestas, inevitavelmente inúmeras. Sugiro que Sozaboy, de Ken Saro-Wiwa, é exemplo disso.

Como se sabe, sem se confundir com a ideia de educação (Erziehung), mas de alguma forma também a incluindo, a palavra Bildung, costumeiramente traduzida para o português como "formação", refere-se ao processo de construção ou "aperfeiçoamento" intelectual do sujeito em meio à busca do conhecimento de si e de seu lugar no mundo. Conforme Wilma Patricia Maas (2000, p. 27) esclarece, a Bildung deve ser entendida como resultado de um processo "que não pode ser atingido apenas pela atividade metódica da educação", ou seja, ela pressupõe uma performance espontânea do indivíduo, capaz de promover o seu "melhoramento" como sujeito no mundo. Nesse sentido, o vínculo imediato com a noção de Iluminismo ou Esclarecimento (Aufklärung) torna-se evidente: a Bildung diz respeito tanto ao encontro do sujeito consigo mesmo por meio da razão quanto à "saída do homem de sua menoridade, da qual ele próprio é culpado. A menoridade é a incapacidade de fazer uso de seu entendimento sem a direção de outro indivíduo" (KANT, 1985, p. 100). Trata-se, em suma, de um termo muito caro à filosofia e teoria estética alemãs dos séculos XVIII e XIX, vinculado, entre outros, principalmente aos nomes de Herder, Schiller, Schlegel, Goethe, Hegel e Humboldt. Conforme lemos na célebre formulação de Schiller (2011, p. 25),

A natureza não trata melhor o homem que suas demais obras: age em seu lugar onde ele ainda não pode agir por si mesmo como inteligência livre. O que o faz homem, porém, é justamente não se bastar com o que dele a natureza fez, mas ser capaz de refazer regressivamente com a razão os passos que ela antecipou nele, de transformar a obra da privação em obra de sua livre escolha e de elevar a necessidade física à necessidade moral.

O que diferencia o homem das demais obras da natureza seria, pois, a capacidade de controlar e produzir a sua própria existência e atuação no mundo utilizando a razão. A esse campo lexical, associa-se, logicamente, todo o ideário moderno que inclui conceitos como "espírito", "cultura”, "educação", "liberdade”, "autonomia”, "humanidade”, "trabalho", "formação", "moral”, "belo", "progresso", "felicidade”, "ciência”, além de uma noção de tempo que neles opera e que lhes é particular. O sujeito emancipado, por meio de seu processo formativo, em vez de simplesmente acomodar-se ao mundo como um de seus objetos, tornase capaz de refletir sobre a sua condição e de, portanto, fabricá-la ou modificá-la segundo 
os seus próprios termos. Em resumo, em oposição à adaptação forçada a um contexto que agride e reduz o ser humano à luta pela sobrevivência, seja sobrevivência à guerra ou ao mercado de trabalho - luta esta por vezes indicada também pelo modo como os corpos se docilizam voluntariamente em busca da semiformação que possa lhes assegurar um trabalho ou carreira de conforto posterior -, a Bildung pressupõe um gesto menos passivo ou reativo e mais afirmativo, algo que demanda justamente autonomia, coragem e liberdade. A formação concede ao homem a possibilidade de elevar-se para além de si mesmo, alçando-o a uma condição quase que divina; conforme lemos em um dos fragmentos de Schlegel (1997, p. 94), “Todo homem bom se torna cada vez mais Deus. Tornar-se Deus, ser homem, formar-se, são expressões que significam a mesma coisa".

O termo Bildungsroman resulta, por sua vez, da noção de Bildung associada ao romance, gênero literário burguês que substitui o herói da épica pelo retrato do ser humano comum em seu "desabrigo transcendental", segundo a expressão de Lukács (2000, p. 38). Abandonado à sua própria sorte pelos deuses que antes o protegiam, o homem deve agora valer-se de sua interioridade e capacidade reflexiva para atribuir sentido à existência e à vida em comum, que já não corresponde mais a uma coletividade orientada desde um ponto maior, sempre verdadeiro e externo a ela. O "romance de formação", tal como o termo é traduzido para o português, nada mais é do que o esboço literário da busca do ser humano por um "auto-aperfeiçoamento" que resulta não de regras ditadas de um outro lugar, mas sim de uma ética particular estabelecida a partir da presença ativa no mundo. Nas palavras de Maas (2000, p. 13), "a formação do jovem de família burguesa, seu desejo de aperfeiçoamento como indivíduo, mas também como classe, coincidem historicamente com a 'cidadania' do gênero romance". Assim, o Bildungsroman arrasta consigo aquela mesma terminologia associada à Bildung e vinculada às ideias de indivíduo e autonomia.

O romance considerado exemplo paradigmático de Bildungsroman é, como se sabe, Os anos de aprendizado de Wilhelm Meister, de Goethe. É nele que Karl Morgenstern se apoia para empregar o termo pela primeira vez, em 1810, em sua tentativa de estabelecer um denominador comum para os romances que representam "a formação do protagonista em seu início e trajetória até alcançar um determinado grau de perfectibilidade" (apud MAAS, 2000, p. 19). Em uma das passagens mais conhecidas do romance, Wilhelm expressa, em carta destinada a seu cunhado, Werner, um desejo de "formar-se" que traduz com exatidão a noção de Bildung aqui em pauta e que caracteriza o ideal de "formação universal" de aspiração burguesa: "Para dizer-te em uma palavra: instruir-me a mim mesmo, tal como sou, tem sido obscuramente meu desejo e minha intenção, desde a infância. Ainda conservo essa disposição, com a diferença de que agora vislumbro com mais clareza os meios que me permitirão realizá-los" (GOETHE, 2006, p. 284). No processo de formação narrado no romance, Wilhelm encontra-se preso entre, por um lado, o desejo de desenvolver as suas aptidões artísticas e intelectuais e, por outro lado, a tendência mais imediata, alimentada pelos laços familiares burgueses, de engajar-se na atividade econômica e lançar-se de pronto ao acúmulo de dinheiro e capitais. A resolução final do romance sinaliza um desfecho característico do Bildungsroman, , momento em que o protagonista vislumbra aquele que seria, enfim, o seu "verdadeiro" lugar, responsável por conferir harmonia à sua existência e suavizar a tensão entre o "eu” e o mundo: “ - Não sei o valor de um reino - replicou Wi- 
lhelm -, mas sei que alcancei uma felicidade que não mereço e que não trocaria por nada no mundo" (GOETHE, 2006, p. 575). Ao encontrar a felicidade pessoal, o protagonista consegue superar seu individualismo imediato para poder formular uma imagem mais complexa e coletiva do mundo objetivo.

Se o "romance de formação" encontra sua expressão mais evidente na obra de Goethe, onde a busca de si mesmo e do "auto-aperfeiçoamento" final opera como ponto de convergência para os episódios narrados, os usos e aplicações posteriores do termo passam gradativamente a se vincular muito mais a enredos voltados para a descrição da trajetória de formação inicial do sujeito, suas aventuras e desventuras, do que precisamente ao horizonte conceitual que em Goethe regula uma jornada formativa de natureza teleológica: "harmonia", "razão", sensibilidade", "autonomia" etc. Em outras palavras, reduzido a um ponto de partida estritamente temático e afastado do lugar filosófico que estrutura conceitualmente o Bildungsroman característico do espírito alemão dos séculos XVIII e XIX, ou mesmo dos discursos de nação e das literaturas nacionais então dominantes, o que temos é um simulacro de conceito de ampla aplicação, mas que, a bem da verdade, diz muito pouco sobre a singularidade dos artefatos a que se associa. Não por acaso, tomando como exemplo o conhecido caso brasileiro, costuma-se ler O Ateneu, de Raul Pompeia, como um "romance de formação", haja vista o retrato tecido pelo autor do período inicial da vida de Sérgio em seu confinamento na instituição escolar de mesmo nome. Vale a pena, entretanto, lançar as seguintes perguntas: o que significa ler O Ateneu como um Bildungsroman se é a própria Bildung que vemos ali posta em xeque? Cabe falar em formação quando, ao fim do processo formativo inicial, a educação se vê reduzida à mercadoria, a infância é tão somente a antecipação da luta pela sobrevivência no mercado de trabalho, a constituição psíquica do sujeito é um apanhado de confusão e ressentimento e as instituições sociais ardem em um fogo que nada purifica?

Ora, talvez a dissolução do sujeito, a instrumentalidade da razão e a consequente crise da ciência e da própria teoria, o fim do humanismo, o império do mercado, o esvaziamento dos vínculos comunitários, a crise migratória, a onipotência e onipresença da indústria cultural, a descrença nos chamados metadiscursos, a crise ambiental e humanitária sem precedentes, a substituição da educação ou formação pela semiformação e pela "gestão de si" etc., talvez tudo isso seja suficiente para comprometer a pertinência de falarmos ainda hoje em Bildung ou Bildungsroman. Difícil crer que termos como "razão", "cultura", "educação", "liberdade", “autonomia", "humanidade”, "trabalho", "moral”, "progresso" - eles mesmos dependentes das instituições modernas que hoje são capazes tão somente de assegurar a produção e persistência do contrário daquilo que aparentemente defendem (escolas, prisões, fábricas, quartéis, hospitais, asilos, clínicas etc.) - passem intocados pela crise dos discursos filosóficos e das instituições que antes os amparavam, e com o seu abalo vê-se precarizada, paralelamente, a imagem de formação humana que lhe é correspondente. Seja como for, o que cabe aqui assinalar é que Sozaboy, romance de Ken Saro-Wiwa, pede para si uma outra epistemologia, uma outra conceituação, diferente dos termos ora em questão. 


\section{SOZABOY: ROMANCE DE DEFORMAÇÃO}

A primeira coisa que chama a atenção em Sozaboy, de Ken Saro-Wiwa, é o grau de alienação e desentendimento de Mene em relação ao conflito que se aproxima, uma naiveté aguda e incurável que, talvez por isso mesmo, acaba negativamente alçada à condição de crítica no romance, já que o personagem, em sua apreciação precária da guerra, encarna de imediato a capacidade destrutiva e ilusória desta. Afinal de contas, a brutalidade da guerra não estaria desde já inscrita no próprio poder de capturar e controlar as subjetividades que, mesmo sem compreendê-la, desejam dela participar? Esse é exatamente o caso de Mene, expresso nas leituras equivocadas que estimulam o seu fascínio pelo exército e por tudo que o cerca; para quem não pode ser "doutor" - "When I passed the elementary six exam, I wanted to go to secondary school but my mama told me that she cannot pay the fees. The thing pained me bad bad because I wanted to be big man like lawyer or doctor riding car and talking big big English" (SARO-WIWA, 1994, p. 11) ${ }^{7}$-, resta a alternativa do empoderamento pelas armas: "I must go to join army immediately. I will wear uniform like those boys. [...] As I am marching with gun and singing, prouding, all the people will come and look at me" (SARO-WIWA, 1994, p. 54). ${ }^{8}$ Com efeito, a realidade da guerra é mascarada por aquilo que Mene chama de big grammar, uso intimidante de um inglês formal que é tanto admirado quanto incompreendido pelos habitantes de Dukana, submetidos como estão ao funcionamento sedutor e propagandista de códigos, regras e comportamentos a eles estranhos. Conforme Michael North (2001, p. 103) observa,

As recorrentes descrições da retórica governamental e militar em termos de tamanho, como se tal linguagem de fato tivesse substância material, expressam a situação do povo de Dukana, que não pode apreciar como língua as palavras que é incapaz compreender, e por isso tem de sofrer as consequências em absoluta ignorância. [...] Roubados primeiramente de sua compreensão e depois de sua vontade própria, as pessoas de Dukana são assassinadas pela grande gramática (big grammar) muito antes mesmo de serem eliminadas por bombas e armas.

A guerra e sua máquina de capturar operam em Dukana por meio de uma gramática da sedução que os habitantes não conseguem desativar, e que, por isso mesmo, os condena a vivenciar um embate incompreendido numa espécie de ciclicidade histórica ininterrupta. Para dizê-lo de outra forma, o conflito que agora se avizinha não é de todo diferente daquele mesmo conflito que décadas atrás conseguira apanhar Zaza, amigo mais velho de Mene, em seu mecanismo, e do qual ele hoje muito se orgulha nas memórias reconstruídas por meio de uma precária narrativa supostamente vencedora. Quando o sal parou de chegar a Dukana há muito tempo atrás, tornando a vida de todas as pessoas insuportável, Zaza não hesitou em se colocar à disposição do exército para que o sal pudesse voltar à região: “I just

7 "Quando passei na prova do sexto ano, queria ir para o secundário, mas minha mãe não tinha dinheiro para pagar as taxas. Isso doeu muito, pois eu queria me tornar um grande homem, como um advogado ou doutor, dirigindo o carro e falando um inglês muito bonito".

8 "Tenho que entrar no exército, imediatamente. Vou usar uniforme, como aqueles rapazes. [...] Quando eu marchar com a arma e cantando, orgulhoso, todas as pessoas virão me olhar”. 
ask them why no salt? And they talk that Hitla is the man who is stopping the salt from reaching Dukana. I said this Hitla must be nonsense foolish man otherwise why will he stop salt from reaching Dukana? Does he want everybody to die? Well, I cannot allow my people in Dukana to die. So I said I must join army [...]"” (SARO-WIWA, 1994, p. 26). ${ }^{9}$ Quando Zaza se apresenta ao exército, expondo seu desejo de lutar contra Hitla para que volte a haver sal em Dukana, o D. O. (District Officer, "Oficial de Distrito”) apenas dá uma risadinha (“'So the D.O. began to laugh small small”') e diz que fará de Zaza um soldado. A alienação de Zaza em relação ao conflito fica evidente a partir de seu relato posterior:

'Forest everywhere. And Hitla plenty for that forest. You kill Hitla today, tomorrow one hundred Hitla appear. You cut him leg today, tomorrow he get twenty legs. [...] No gun in our hand oh. Only the white people get gun and they were behind us. [...] Everyday we were fighting and cutting him, but still he will come again. The more we kill him the more he comes. Praps that is why they call him bastard. We were fighting and cutting him for two years and then he will still come again after we have killed him'. (SARO-WIWA, 1994, p. 29). ${ }^{10}$

Dessa vez, cumprindo o destino histórico de um povo que deve dar corpo a uma guerra cujos termos e motivos situam-se em lugares distantes, chegou a vez de Mene e das novas gerações de realizar o mesmo "sacrifício" feito por Zaza no passado: "I cannot fight again. I have killed my own Hitla. Let Mene them go and fight"” (SARO-WIWA, 1994, p. ??). ${ }^{11}$ E trata-se, de fato, de uma entrega ou desistência de si, gesto que demanda do sujeito, antes de mais nada, a destituição simbólica do nome que até então conferia estabilidade e reconhecimento do papel desempenhado em meio aos demais membros da comunidade; no lugar de Mene, aprendiz de motorista e habitante de Dukana, vemos surgir Sozaboy, a identidade desterritorializada assumida para o conflito, capaz de se apropriar do sujeito de antes e de reconfigurar a sua subjetividade: "So from that time wherever I go people are calling me 'Sozaboy,' 'Sozaboy'. Even I am very famous in Dukana sef. [...] Myself, I was prouding plenty. When they call me 'Sozaboy' I will answer well well. Even I begin to tell people that my name is Sozaboy. [...] I like the name well well” (SARO-WIWA, 1994, p. 65). ${ }^{12}$ Tal como Celina Gomes (2015, p. 53) comenta em sua leitura do romance, Mene não percebe que, "ao rejeitar seu nome e tornar-se, efetivamente, um Sozaboy, adere e aceita um rótulo que rouba sua identidade e o configura como só mais um entre tantos outros soldados". Tornarse Sozaboy significa, nesse contexto de completa ignorância e alienação, adotar um nome genérico que inaugura o processo de desidentificação, perda de si e precarização daqueles

\footnotetext{
9 “'Eu apenas pergunto por que não há sal? E eles dizem que Hitla é o homem que está impedindo o sal de chegar a Dukana. Eu disse que esse Hitla só podia ser um idiota estúpido para não deixar o sal chegar a Dukana. Ele quer que todo mundo morra? Bom, eu não posso deixar que as pessoas em Dukana morram. Então eu disse que iria para o exército [...]"'. 10 “"Floresta pra todo lado. E cheio de Hitla naquela floresta. Você mata Hitla hoje, amanhã aparecem cem Hitla. Você corta a perna dele hoje, amanhã ele tem vinte pernas. [...] Nenhuma arma em nossas mãos. Apenas os brancos têm armas, e eles ficam atrás de nós. [...] Todos os diaslutando e cortando ele, mas ainda assim ele vem de novo. Quanto mais vocêmata ele, mais elevem. Talvez por isso que chamam ele de canalha. Lutamos e cortamos ele por dois anos, e ele ainda voltava depois de matarmos ele"'. 11 “Eu não posso lutar de novo. Já matei meu próprio Hitla. Mene que vá e lute”.

12 “A partir de então onde quer que eu vá as pessoas me chamam de 'Sozaboy', 'Sozaboy'. Eu estou até famoso em Dukana. [...] Eu estava gostando muito de tudo isso. Quando me chamam de 'Sozaboy', eu respondo bem bem feliz. Eu até comecei a dizer às pessoas que meu nome é Sozaboy. [...] Gosto muito muito do nome”.
} 
mesmos laços comunitários que, paradoxalmente, parecem empurrá-lo para o conflito, fazendo a roda da destruição girar uma vez mais.

A big grammar de que Mene nos fala com admiração é capaz, portanto, de naturalizar uma epistemologia da destruição que faz com que os moradores de Dukana se entreguem voluntariamente à guerra e à perda de seus vínculos sociais. Interromper esse ciclo significa, nesse esquema, trabalhar a partir de uma outra epistemologia, ou melhor, violentar a "grande gramática" por meio de uma linguagem ou terminologia de uma só vez comunitária e singular; aliás, talvez seja justamente isso que Saro-Wiwa esteja tentando fabricar com o seu rotten English, um uso do inglês ao mesmo tempo poético, particular e de difícil tradução ou assimilação, mas partilhado no romance pelos habitantes de Dukana. Mais uma vez, segundo a formulação de Michael North (2001, p. 111), "a solução de Saro-Wiwa não é alcançar uma autenticidade ou traduzibilidade linguística, mas sim adotar uma linguagem que não pertença a ninguém, na qual ninguém se sinta em casa e que, dessa forma, registre uma situação universal de incompreensão ou de tradução equivocada”. Mais importante que isso, o rotten English, não pertencendo a ninguém, passa a ser capaz de, em sua artificialidade, denunciar criticamente a falsidade também da gramática oficial, isso sem deixar-se domesticar no meio do caminho, tecendo no próprio processo narrativo a crítica da situação narrada.

É bem verdade que Mene se dá conta, ao fim da narrativa, de que a guerra "[...] is useless nonsense and all this uniform and everything is just to cause confusion and make porson fine like goat that they have make fat and ready to kill for chop during Christmas" (SARO-WIWA, 1994, p. 127). ${ }^{13}$ Da mesma forma, é bem verdade que, como declara Maureen N. Eke (2000), ao fim do romance, Mene desconfia de modo mais integral de vários dos relatos e pessoas que organizam e estruturam a vida em Dukana, tomando como exemplos mais evidentes da corrupção generalizada os próprios "líderes morais" da comunidade, o Chefe Birabee, que se beneficia diretamente do medo generalizado, e o Pastor Barika, um dos agenciadores mais eficientes desse medo; a velha Dukana converte-se num lugar que já não pode mais ser conciliado com as "memórias" de guerra. Há, nesse sentido, por parte de Mene, uma "tomada de consciência" quanto ao que se passa a seu redor. Chamar essa "tomada de consciência" de "formação", no entanto, projetando sobre o relato as sombras da Bildung, significa, sem dúvida, preservar justamente aquilo que para Mene já não pode mais ser poupado, destituindo o conceito dos usos positivados que ele abriga em seu percurso histórico. Para dizê-lo de forma bastante clara: como resultado da guerra, Mene perde seu nome, perde sua mãe - uma das poucas pessoas a se opor ao seu ingresso no exército -, perde seus amigos, perde sua esposa Agnes, perde, enfim, sua comunidade, e parte numa errância incerta, talvez infinita, como um fantasma que compreende não pertencer a lugar algum; talvez seu destino seja sempre o de "correr, correr, correr, correr e correr", como ele mesmo declara ao fim da narrativa. Em sua errância e orfandade final, Mene, menos que da Bildung ou do Bildungsroman, aproxima-se muito mais de outros personagens modernos sem nome, identidade ou comunidade, referidos apenas por meio de sombras, restos iden-

13 A guerra "[...] é uma bobagem sem sentido e toda essa coisa de uniforme e tudo mais serve apenas para causar confusão e fazer com que a pessoa se comporte como uma cabra que eles engordam e deixam pronta para ser abatida e servida durante o Natal”. 
titários ou siglas, convictos tão somente do não pertencimento: Josef K. ou K., de Kafka, Molloy ou o Inominável, de Beckett, Juan Preciado, de Juan Rulfo, entre tantos outros, sujeitos partidos, fragmentados, incompreendidos e sem conseguir compreender com clareza aquilo que os destrói. São órfãos

[...] em um mundo alienado e fragmentado até o limite de sua total incompreensibilidade. São seres arrancados de suas origens biológicas e linguísticas em um sentido ontológico radical. Sua existência cortou todos os vínculos que a uniam à natureza e à comunidade humana. Psicologicamente, distinguem-se como sujeitos sem memória, sem experiências, sem sonhos. Sujeitos vazios. Podemos falar de uma orfandade social e cósmica e de um ser-no-mundo órfão em todos esses romances. (SUBIRATS, 2016, p. 246).

Em uma das passagens mais importantes de Sozaboy, prova de que o exílio passa a ser, para o personagem principal do romance, uma realidade da qual já não há mais como escapar, Mene-Sozaboy retorna para Dukana e se vê desapropriado pelos demais tanto do seu nome de batismo quando da alcunha recebida exclusivamente para a guerra; Mene já não é mais nem ele próprio, nem Sozaboy: ele já não é ninguém, visto pelos antigos amigos como um fantasma, uma vítima fatal do conflito: "You have already dead long ago. [...] You are not our own Sozaboy. You are ghost'” (SARO-WIWA, 1994, p. 131). ${ }^{14}$ É como um fantasma, uma doença, uma maldição, um desterrado, um órfão errante, um sujeito sem nome, identidade, família ou comunidade, que Mene vê encerrado seu suposto ciclo formativo, formação esta, então, que se resume a uma constatação de que a guerra não vale a pena, conclusão autoevidente alcançada à custa de qualquer traço definidor de seu caráter. Juju, smallpox, ghost ("feiticeiro", "varíola", "fantasma") - menos que um nome, o que Mene conquista para si como atributos seus são traços negativos que pairam sobre ele como uma maldição lançada durante a guerra, impedindo-o de qualquer contato efetivo ou significativo com os outros membros de sua comunidade: "Well, Sozaboy, juju, smallpox, that is what I used to call you, and that is what you are. [...] Since the war ended and everybody came back, they are saying that you have already dead since the war started"' (SARO-WIWA, 1994, p. 178). ${ }^{15}$ Em resumo, como fantasma retornado da guerra, resta a Mene-Sozaboy-Fantasma correr sem direção, sem destino e sem previsão de chegada; as portas de Dukana agora estão todas fechadas para ele: "And as I was going, I was just thinking how the war have spoiled my town Dukana, uselessed many people, killed many others, killed my mama and my wife, [...] and now it have made me like porson wey get leprosy because I have no town again" (SARO-WIWA, 1994, p. 181). ${ }^{16}$

\footnotetext{
14 “"Você já morreu há muito tempo. [...] Você não é o nosso Sozaboy. Você é um fantasma”.

15 “Bem, Sozaboy, feiticeiro, varíola, isso é o que eu costumava chamar você, e isso é o que você é. [...] Desde que a guerra acabou e todos retornaram, eles começaram a dizer que você morreu quando a guerra começou”." 16 "Enquanto eu ia, fiquei pensando como a guerra destruiu a minha cidade Dukana, acabou com várias pessoas, matou várias outras, matou minha mãe e minha esposa, [...] e como agora a guerra fez de mim um leproso que não pertence a nenhum lugar".
} 


\section{APONTAMENTOS FINAIS}

Uma das questões fundamentais colocadas pelo romance Sozaboy, de Ken Saro-Wiwa, diz respeito à gradativa conquista do outro como resultado dos efeitos de uma linguagem ou epistemologia da sedução capaz de convocar, extinguir e neutralizar-se ao fim do processo, viabilizando uma nova atuação posterior e estabelecendo os ciclos de destruição pela guerra representados no livro por Mene e Zaza. Não é essa a principal conclusão do estudo de Michael North sobre Sozaboy e o "inglês roto" de Saro-Wiwa? Em certo momento, "Mene aprende que o poder prometido pela grande gramática se confunde com a própria morte" (NORTH, 2001, p. 112), ou melhor, Mene percebe que a morte procede por meio da linguagem, destruindo o sujeito também a partir de dentro. As sutis trocas de nomes operadas no romance - de Mene para Sozaboy, de Sozaboy para Juju, smallpox, ghost - indicam a progressiva perda de si inscrita no próprio domínio da linguagem: é com entusiasmo inicial que o narrador descreve a violência empreendida contra os traços singulares e as posições sociais que antes o definiam - "Mene", "aprendiz de motorista", "amigo", "filho", "marido" etc. -, para apenas tardiamente perceber a sua existência por todos comparada a um vírus ameaçador e indesejado que circula por uma cidade já incapaz de reconhecer os seus: "You see, Dukana people are saying that although you have already dead, you have become ghost and sometime you can appear as proper person [...]. And now that the war have ended, you have returned again as ghost to Dukana to worry those who have not yet dead'" (SARO -WIWA, 1985, p. 179). ${ }^{17}$

Nesse sentido, o "inglês roto" pode ser lido, conforme sugerido anteriormente, como uma forma de resistência à "grande gramática" e sua maquinaria de captura, isto é, como uma linguagem tanto poética, criativa e singular, quanto, acima de tudo, de difícil apropriação ou domesticação. Lançar contra o romance a crítica de que "ninguém fala assim" ou de que a linguagem da narrativa é inconsistente significaria não compreender a política do "inglês roto" ali posta em prática, uma vez que Saro-Wiwa parece incitar o uso de uma dicção que, ao desviar-se de si mesma, atua politicamente na resistência aos procedimentos de captura e mimetização presentes na fórmula da guerra. Vale ressaltar que, se por um lado, o fim de Mene corresponde à sua dissolução enquanto sujeito e à impossibilidade de se comunicar com os seus, o "inglês roto", por outro lado, em sua corruptela da linguagem oficial, consegue abrir um rastro de esperança em torno de um idioma por vir capaz de violentar a fórmula linguística da guerra e as estruturas de poder nela vigentes. A rigor, as linhas finais do romance, ao mesmo tempo que indicam a errância existencial que Mene terá de cumprir como seu destino inevitável, ironizam e parodiam mais uma vez os formalismos que conduzem o aparato burocrático e seus dispositivos reguladores e que podem ser facilmente deslocados para a maquinaria da guerra: "And I was thinking how I was prouding before to go to soza and call myself Sozaboy. But now if anybody say anything about war or even fight, I

17 “'Veja, os moradores de Dukana estão dizendo que, apesar de já estar morto, você se tornou um fantasma e às vezes pode aparecer como pessoa de verdade [...]. E agora que a guerra acabou, você retornou de novo a Dukana como fantasma para incomodar aqueles que ainda não morreram"”. 
will just run and run and run and run and run. Believe me yours sincerely" (SARO-WIWA, 1985, p. 181, grifo meu). ${ }^{18}$

Cabe aqui, em suma, após essas considerações sobre Sozaboy e a política do "inglês roto", lançar uma provocação final que retoma a principal questão trabalhada ao longo deste texto: se Mene é destruído também pelo uso de uma linguagem a ele estranha, muito embora fascinante, e se a obra de Saro-Wiwa empreende uma resistência a essa linguagem justamente recorrendo a uma diç̧ão literária desviante que não pertence a ninguém, valer-se do campo conceitual da Bildung ou do Bildungsroman - um campo conceitual que, é importante dizer, jamais abrigaria ou teria sido projetado sobre um contexto tão diferente quanto aquele narrado no romance - por acaso não seria repetir no âmbito da crítica literária a mesma imposição terminológica que aprisiona os habitantes de Dukana? Ora, para além do simples fato de que Sozaboy só se inscreve na noção de Bildungsroman após uma incisiva ginástica teórico-conceitual capaz de ampliar significativamente o escopo da categoria em questão - a ponto de permitir, inclusive, que a própria literatura possa ser desde sempre lida a partir dos signos da formação e da Bildung -, aplicar conceitos exteriores ao romance de Saro-Wiwa para explicar o seu funcionamento não significaria, num gesto paradoxal pouco produtivo, negar ao romance a sua própria terminologia, repetindo o exercício de silenciamento descrito por Mene em sua trajetória "(de)formativa"? Diante dessa "grande gramática" impositiva, talvez caiba aqui reencenar as palavras do personagemnarrador de Sozaboy em sua verdadeira potência crítica: "Fine fine English. Big big words".

\section{REFERÊNCIAS}

ACHEBE, Chinua. A educação de uma criança sob o protetorado britânico. São Paulo: Companhia das Letras, 2012.

EKE, Maureen N. The Novel: Sozaboy: a Novel in Rotten English. In: MCLUCKIE, Craig W., MCPHAIL, Aubrey (Eds.). Ken Saro-Wiwa: Writer and Political Activist. London: Lynne Rienner Publishers, 2000.

GOETHE, J. W. Os anos de aprendizado de Wilhelm Meister. Trad. Nicolino Simone Neto. São Paulo: Ensaio, 1994.

GOMES, Celina de Oliveira Barbosa. Desalienação e a configuração do Bildungsroman em Sozaboy, de Ken Saro-Wiwa. Dissertação (Mestrado em Estudos Literários). Universidade Estadual de Londrina, Londrina: 2015, $108 \mathrm{f}$.

KANT, Immanuel. Reposta à pergunta: Que é "Esclarecimento"? In: Textos seletos. 2. ed. Trad. Raimundo Vier. Petrópolis: Vozes, 1985.

18 "E lembro como fiquei feliz antes quando me tornei soldado e quando passei a me chamar Sozaboy. Mas agora se alguém disser qualquer coisa sobre guerra ou combate, vou apenas correr, correr, correr, correr e correr. Acredite em mim. Atenciosamente". 
LUKÁCS, Georg. A teoria do romance. Trad. José Marcos Mariani de Macedo. São Paulo: Duas Cidades; Ed. 34, 2000.

MASS, Wilma Patrícia. O cânone mínimo: o Bildungsroman na história da literatura. São Paulo: Editora UNESP, 2000.

M’BOKOLO, Elikia. África Negra: história e civilizações. Tomo II (Do século XIX aos nossos dias). Salvador: EDUFBA; São Paulo: Casa das Áfricas, 2011.

NNOLIM, Charles E. Approaches to the African Novel. 3. ed. Lagos: Malthouse, 2010.

NORTH, Michael. Ken Saro-Wiwa's Sozaboy: The Politics of the "Rotten English". Public Culture. England, v. 13, n. 1, apr/aug. 2001, p. 97-112.

SARO-WIWA, Ken. Sozaboy. New York: Longman Publishing Group, 1994.

SCHILlER, F. A educação estética do homem. Trad. Roberto Schwarz e Márcio Suzuki. São Paulo: Iluminuras, 2011.

SCHLEGEL, Friedrich. O dialeto dos fragmentos. Trad. Márcio Suzuki. São Paulo: Iluminuras, 1997.

SIMOLA, Raisa. The Question of Identity during the Nigerian Civil War (1967-1970) in the Fiction of Flora Nwapa and Ken Saro-Wiwa. In: PALMBERG, Mai (Org.). National Identity and Democracy in Africa. Cape Town: Capture Press, 1999, p. 80-100.

SUBIRATS, Eduardo. "Kafka, Rulfo, Beckett: retorno ao mito". In: CECHINEL, André. (Org.). O lugar da teoria literária. Florianópolis: EdUFSC; Criciúma: Edinesc, 2016, p. 241-260.

Recebido em 16 de agosto de 2017 Aceito em 20 de outubro de 2017 
